\title{
Prediction of 2-year work participation in sickness absentees with neck or shoulder pain: the contribution of demographic, patient-reported, clinical and imaging information
}

Line Thorndal Moll ${ }^{1,2,3^{*}}$ (D), Anne Mette Schmidt ${ }^{1,2,4}$, Christina Malmose Stapelfeldt ${ }^{1,2}$, Merete Labriola ${ }^{1,2}$, Ole Kudsk Jensen ${ }^{3}$, Morten Wasmod Kindt ${ }^{5}$, Tue Secher Jensen ${ }^{5,6}$ and Berit Schiøttz-Christensen ${ }^{7}$

\begin{abstract}
Background: In cases of neck and shoulder pain, the responsibility for assessing work prognosis is held by clinicians with access to different domains of information. One of these domains is magnetic resonance imaging $(\mathrm{MRI})$, and although MRI is increasingly used, it is unknown which domains of information contribute the most to the prediction of work prognosis. This retrospective cohort study explored the contribution of demographic, patient-reported, clinical, and MRI information to the prediction of work participation in sickness absentees with neck or shoulder pain.

Methods: From a secondary care setting, 168 sickness absentees with neck or shoulder pain were included. Based on registry data, a successful work outcome was defined as $\geq 50 \%$ work participation score (WPS) from Weeks 1 to 104 after enrolment. Prognostic variables were categorized into four domains (demographic, patient-reported, clinical, and MRI) resembling the order of information obtained in a clinical setting. Crude logistic regression analyses were used to identify prognostic variables for each domain $(p<0.2)$. This was followed by multivariable analyses including the identified variables in a domain-wise order. For each added domain, the probability of successful WPS was dichotomized leaving two possible classifications: $\geq 50 \%$ chance of successful WPS or not. In cross-tabulations of chance and the actual WPS outcome, positive and negative predictive values (PPV and NPV), sensitivity, specificity and area under the curve (AUC) were calculated.
\end{abstract}

Results: The combination of demographic and patient-reported variables yielded an NPV of 0.72 and a PPV of 0.67, while specificity was 0.82 , sensitivity 0.54 and AUC 0.77 . None of these values improved notably by adding clinical and MRI variables as predictors of successful WPS.

Conclusions: These results suggest that - among sickness absentees with neck or shoulder pain - clinical and MRI variables provide no additional information for the prediction of work participation compared with only demographic and patient-reported information.

Keywords: Prognosis, Prediction, Sick leave, Neck pain, Shoulder pain, Magnetic resonance imaging

\footnotetext{
* Correspondence: linethor@rm.dk

'DEFACTUM, P.P. Oerums Gade 11, bygn. 1B, Aarhus C, DK-8000 Aarhus,

Central Denmark Region, Denmark

${ }^{2}$ Section of Clinical Social Medicine and Rehabilitation, Department of Public

Health, Aarhus University, P.P. Oerums Gade 9-11, bygn. 1B, Aarhus C,

DK-8000 Aarhus, Denmark

Full list of author information is available at the end of the article
}

(c) The Author(s). 2019 Open Access This article is distributed under the terms of the Creative Commons Attribution 4.0 International License (http://creativecommons.org/licenses/by/4.0/), which permits unrestricted use, distribution, and reproduction in any medium, provided you give appropriate credit to the original author(s) and the source, provide a link to the Creative Commons license, and indicate if changes were made. The Creative Commons Public Domain Dedication waiver (http://creativecommons.org/publicdomain/zero/1.0/) applies to the data made available in this article, unless otherwise stated. 


\section{Background}

During sick leave, estimating work prognosis is important as it helps guide expectations for all involved stakeholders. The responsibility for this usually resides with healthcare professionals and it is often requested of them by authorities involved in return-to-work (RTW) coordination and the disbursement of social benefits, i.e. sickness benefits. When assessing work prognosis, healthcare professionals have access to different domains of information. In a clinical setting, such information is typically obtained in the following order: 1) demographics are known already when scheduling the clinical encounter, and are followed by 2) patient-reported information which is a necessary prerequisite for performing 3) a focused clinical examination, and deciding whether 4) imaging is needed (e.g. magnetic resonance imaging (MRI)).

From this range of information, the literature offers insight into known prognostic factors. From the demographic domain, older age is negatively associated with RTW [1, 2], while for the impact of sex, results are conflicting [1-3]. Patient-reported information that is negatively associated with work outcomes includes symptom intensity, sick leave duration [1, 3], ongoing workers' compensation claim [4] and high physical work demands [1]. From the clinical domain, low back pain studies have found a negative association between radiating pain and RTW in the acute phase $(<6$ weeks) [5] and moderate evidence for no association with RTW in the sub-acute and chronic phases [2]. Also from the clinical domain, fibromyalgia is associated with poor work participation [6]. From the MRI domain, a single study involving sickness absentees with low back pain found Modic type 1 changes on MRI to predict unsuccessful RTW [7].

However, the prognostic value of imaging has been described as "a gap in the literature" [8]. This gap still deserves investigation as the number of MRIs has increased more than the prevalence of people suffering from neck and shoulder pain [9-11]. Moreover, the referral patterns have changed over recent years; e.g. in Denmark, not only hospital physicians but also primary care clinicians (physicians and chiropractors) can request MRI. For clinicians in both primary and secondary care, this change in MRI referral patterns has changed the range of information available when estimating work prognosis.

The literature thus offers insight into factors associated with work prognosis. But to our knowledge, no previous studies have examined to what extent the different domains of information contribute to the prediction of work prognosis. Thus healthcare professionals' assessment of work prognosis may be based on gut-feeling rather than evidence. Therefore, the aim of this study was to explore the degree to which demographic, patientreported, clinical, and MRI information contribute to the prediction of work participation in sickness absentees with neck or shoulder pain.

\section{Methods \\ Design and participants}

Using a retrospective cohort design, 168 sickness absentees referred to secondary care for assessment of neck or shoulder pain were included in this study. Neck pain was defined as pain perceived anywhere in the posterior region of the cervical spine. Neck pain may refer to the head, the shoulder, the anterior chest wall or the upper limb [12]. Shoulder pain was defined as pain perceived around the shoulder; it may originate from the neck, any of the three joints adjacent to the shoulder (glenohumeral, acromioclavicular and sternoclavicular joints) or adjacent soft tissues [13]. All participants were part of an RCT [14] that took place from 2009 to 2014 and compared the work outcomes after two different hospitalbased interventions (multidisciplinary vs. brief intervention). The inclusion criteria for the RCT were: sick leave 1-4 months owing to neck or shoulder pain, age 18-60 years, and fluency in Danish. Exclusion criteria were: alcohol or drug addiction, pregnancy, specific musculoskeletal/neurological disease, surgery within the past year, plans for surgery, and primary psychiatric disorder. Further details regarding recruitment and interventions have been described previously [14].

\section{Context (Danish legislation on sickness benefits)}

According to The Danish Sickness Benefit Act, sickness absentees are entitled to financial compensation during sick leave. This compensation can amount to sickness benefits or full wages depending on the union award conditions the worker is entitled to. At the time of the RCT (2009-2014), the employer covered these expenses for the first 21-30 days of a sick leave spell (called the employer paid period) after which the municipality reimbursed some of the employer's expenses (the sickness benefit amount) until RTW was achieved. In Denmark, a special agreement $(\$ 56)$ can be settled upon in cases of recurrent short-term sick leave; it entitles the employer to be reimbursed from the first day of sick leave, thereby reducing the employer's expenses [15].

\section{Outcome: work participation score (WPS)}

Data on work outcomes were supplied by the Danish Register for Evaluation of Marginalization (DREAM) which covers the source of income (financial selfsupport or public transfer benefits) on a weekly basis since July 1991. The registrations are ordered hierarchically; if different transfer benefit codes are registered in the same week, the highest-ranking code will overwrite the others. Sickness benefits have a high rank and are 
only overwritten in cases of emigration, age-related pensions or death [16].

The work participation score (WPS) is a fraction yielding scores between 0 and 100\% [17]. The numerator comprises the number of weeks with financial selfsupport (interpreted as working weeks) as well as weeks with state education fund grants and related benefits (benefits granted in cases of re-education). The denominator comprises the total number of follow-up weeks [17]. In this study, three individuals were granted early retirement. For these three, the denominator comprised the number of follow-up weeks prior to the first appearance of retirement benefits in DREAM. Follow up started at the day of inclusion in the original RCT [14], and a successful outcome was defined as a WPS $\geq 50 \%$ during weeks 1-104 after enrollment. The 50\% threshold was chosen because it has shown substantial to almost perfect agreement compared with other RTW measures [17]. The following denotations were used: successful WPS (s-WPS) $\geq$ $50 \%$ and unsuccessful WPS (u-WPS) <50\%.

\section{Prognostic variables: demographic and patient-reported domain}

These data were collected from questionnaires filled in by the participants prior to their first meeting with the health care professionals in the RCT [14]. The information provided covered demographics (sex and age) and the following patient-reported measures: pain intensity (11-point numeric rating scale) [18], whiplash trauma (yes/no) [19], education ( $\geq 3$ years, yes/no), worker's compensation claim (yes/no) [20], and Örebro Musculoskeletal Pain Screening Questionnaire (ÖMPSQ) [21]. The ÖMPSQ score covers psychosocial risk factors of work disability (e.g. coping abilities, pain beliefs, disability, feelings of anxiety or depression and self-perceived chances of returning to work in 6 months. The ÖMPSQ was originally developed as a screening tool to identify psychosocial risk factors for prolonged disability and sick leave; the higher the score (maximum $=210$ ), the higher the risk of prolonged disability.

\section{Prognostic variables: clinical domain}

Data on radiculopathy and number of tender points [22, 23] came from the clinical examination performed by the rheumatologist prior to enrolment in the RCT [14]. Radiculopathy describes a clinical assessment based on 1) pain radiating from the neck to the upper extremity and 2) one or more positive neurological signs: weakened deep tendon reflexes, decreased muscle strength, dermatomal sensory deficits or a positive foraminal compression test. The reliability of the rheumatologist's tender points count has previously been reported as excellent [24] and a threshold of $\geq 11$ tender points was chosen, since this is still commonly used among clinicians to assess fibromyalgia [25]. In the clinical examination, the tender points count was used as a measure of sensitization of the nociceptive system [26]. Since data were not sufficient to support the diagnosis of fibromyalgia, this term was not used and a dichotomized threshold of the tender points count was used instead. The intervention allocation in the original RCT [14] (multidisciplinary and brief intervention) were also included.

\section{Prognostic variables: MRI domain}

MRI of the cervical spine was ordered for all participants unless clinical examination revealed unambiguous signs of shoulder pathology $(n=7)$. For different reasons, MRI of the cervical spine was only available for 97 of the participants (no access to MRI: $n=32$ and unsatisfactory signal-to-noise ratio assessed by a senior radiologist: $n=$ 32 [27]). All MRIs were de-identified and assessed by the first author (physician with 9 years of post-graduate clinical experience) who was blinded to the study outcomes. The inter-rater reliability of the MRI assessments has previously been reported with un-weighted kappa values ranging from 0.56 to 0.79 [27] while intra-rater reliability yielded kappa values ranging from 0.67 to 0.90 [27]. The MRI variables listed in Table 1 were evaluated at disc levels $\mathrm{C} 2 / \mathrm{C} 3$ to $\mathrm{C} 7 / \mathrm{T} 1$. For each participant, an MRI finding was defined as positive if the finding was present at $\geq 1$ disc level, i.e. two levels with disc height reduction were counted only once.

\section{Statistical analyses}

Crude logistic regression analyses were performed for all baseline variables hypothesized to affect WPS, and variables yielding $p$-values $<0.2$ were carried forward as has been done in other studies [28, 29]. In the multivariable analyses, the prognostic variables were included using a domain-wise approach resembling the typical order of information obtained in a clinical setting. First, demographic variables were included, second patientreported, third clinical, and finally MRI variables - these are referred to as Models 1, 2, 3 and 4. For each model, the probability of s-WPS was calculated and dichotomized, i.e. the participants were classified as having $\geq 50 \%$ chance of $\mathrm{s}$-WPS or not. By comparing the estimated chance of $s$-WPS with whether s-WPS actually happened or not, sensitivity, specificity, positive and negative predictive values (PPV and NPV), and area under the curve (AUC) were calculated. In this study, sensitivity denotes the proportion of u-WPS correctly classified as '<50\% chance of $s$-WPS', and specificity, the proportion of s-WPS that is correctly classified as ' $\geq 50 \%$ chance of $s$-WPS'. In accordance with this, NPV denotes the proportion of sickness absentees classified as ' $\geq 50 \%$ $s$-WPS chance' who actually achieved s-WPS. PPV denotes the proportion of sickness absentees classified as "<50\% s-WPS chance" who did not achieve s-WPS. AUC 
Table 1 Baseline characteristics for sickness absentees with neck or shoulder pain

\begin{tabular}{|c|c|c|c|c|}
\hline \multirow[b]{2}{*}{ Demographics } & \multicolumn{2}{|c|}{ Entire study sample } & \multicolumn{2}{|c|}{ MRI sample } \\
\hline & $\mathrm{N}$ & & $\mathrm{N}_{\mathrm{MRI}}$ & \\
\hline Male sex, n (\%) & 168 & $53(31.5)$ & 97 & $30(30.9)$ \\
\hline Age, median (IQR) & 168 & $40.5(34.5 ; 48.9)$ & 97 & $41.4(35.3 ; 49.9)$ \\
\hline \multicolumn{5}{|l|}{ Patient-reported information } \\
\hline Pain intensity (0-10) last week, median (IQR) & 158 & $7(5 ; 8)$ & 91 & $7(5 ; 8)$ \\
\hline Whiplash trauma, n (\%) & 168 & $24(14.3)$ & 97 & $13(13.4)$ \\
\hline Sick leave duration (months), median (IQR) & 168 & $2.3(1.2 ; 3.0)$ & 97 & $2.3(1.4 ; 3.0)$ \\
\hline ÖMPSQ score, mean (SD) & 161 & $122(23.7)$ & 93 & $121.8(22.1)$ \\
\hline Education $\geq 3$ years, $n$ (\%) & 155 & $29(18.7)$ & 88 & $21(23.9)$ \\
\hline Ongoing worker's compensation claim, n (\%) & 139 & $36(25.9)$ & 82 & $19(23.2)$ \\
\hline \multicolumn{5}{|l|}{ Clinical information } \\
\hline Radiculopathy, n (\%) & 168 & $41(24.4)$ & 97 & $28(28.9)$ \\
\hline$\geq 11$ tender points, $\mathrm{n}(\%)$ & 168 & $57(33.9)$ & 97 & $38(39.2)$ \\
\hline \multicolumn{5}{|l|}{ Intervention group } \\
\hline $\begin{array}{l}\text { Brief intervention, } \mathrm{n}(\%) \\
\text { Multidisciplinary intervention, n (\%) }\end{array}$ & 168 & $\begin{array}{l}83(49.4) \\
85(50.6)\end{array}$ & 97 & $\begin{array}{l}49(50.5) \\
48(49.5)\end{array}$ \\
\hline \multicolumn{5}{|l|}{ MRI information } \\
\hline Kyphosis, n (\%) & & & 97 & $23(23.7)$ \\
\hline Disc height reduction, n (\%) & & & 97 & $71(73.2)$ \\
\hline Bulge, protrusion or extrusion, n (\%) & & & 83 & $69(83.1)$ \\
\hline Spinal canal stenosis, n (\%) & & & 97 & $14(14.4)$ \\
\hline Neural foraminal stenosis, n (\%) & & & 84 & $46(54.8)$ \\
\hline Zygapophyseal osteoarthritis, n (\%) & & & 83 & $39(47.0)$ \\
\hline Uncovertebral osteoarthritis, n (\%) & & & 78 & $37(47.4)$ \\
\hline
\end{tabular}

is a measure of discriminatory ability which describes the probability that a worker achieving s-WPS will be classified as having a better chance than a worker not achieving s-WPS. To ensure comparability between the models, estimates were presented both for the number of individuals with complete data and for the number of individuals with complete data in the adjacent model (e.g. in Model 3: estimates were presented for the 139 individuals with complete data on demographic, patientreported and clinical domains and for the 82 individuals with complete data in Model 4). For each added domain of information, sensitivity, specificity, PPV and NPV were compared between the models. To further appraise the properties of the models, the chance of s-WPS was divided into four categories $(<30 \%, \geq 30 \%$ and $<50 \%$, $\geq$ $50 \%$ and $<70 \%, \geq 70 \%$ ) and tabulations were made to assess whether adding domains of information improved prediction for those with the lowest $(<30 \%)$ and highest $(\geq 70 \%)$ chance of s-WPS. Estimates were reported using 95\% confidence intervals (CIs).

The statistical analyses were performed by the first author who was not involved in the clinical assessment or interventions given in the original RCT [14]. STATA15 statistical software package was used for all statistical analyses (STATA Corp., College Station, Texas, USA).

\section{Nomenclature}

This study explored the associations between prognostic variables and s-WPS. The term "prognostic variable" denotes a baseline variable which is associated with the outcome s-WPS but without making inferences about causality [30]. The terms 'predict'/'prediction' relate to the ability of the models to forecast the prognosis regarding work participation.

\section{Ethics}

All participants provided written informed consent. The study was approved by The Danish Data Protection Agency (J. no. 2012-58-006) and by The Central Denmark Region Committees onHealth Research Ethics (M-20090027).

\section{Results}

One hundred-and-sixty-eight sickness absentees were included. S-WPS was achieved by 100 (59.5\%) of the sickness absentees, i.e. $59.5 \%$ of the sickness absentees had a 
work participation score $\geq 50 \%$ from Week 1 to 104 after enrolment. The proportion achieving s-WPS was similar (59.8\%) in the MRI sample. Baseline characteristics are presented in Table 1.

The crude associations between potential prognostic variables and s-WPS are presented in Table 2. For those variables yielding $p<0.2$, the following associations were seen: Increased odds of s-WPS were found for male sex, radiculopathy and kyphosis. Decreased odds of s-WPS were found for increased sick leave duration (months), increased ÖMPSQ score, ongoing workers' compensation claim, $\geq 11$ tender points, and spinal canal stenosis. The remaining variables from Table 2 did not fulfill the criterion of $p<0.2$ for inclusion in the multivariable analyses

Table 3 presents the predictive values from Models 1-4. As shown, knowledge about only the sex offered an NPV of $0.60(0.52 ; 0.67)$ and a sensitivity of $1.0(0.96 ; 1.0)$ (the 100 sickness absentees who achieved s-WPS were all classified as having $\geq 50 \%$ chance). The PPV could not be calculated since none were classified as having $<50 \%$ chance. By adding patient-reported variables (duration of sick leave, ÖMPSQ score and ongoing workers' compensation claim), the NPV increased to $0.72(0.62 ; 0.81)$ and the PPV to $0.67(0.52 ; 0.80)$ along with increased sensitivity. Adding clinical and MRI information (Models 3 and 4) elicited only minor changes which - based on confidence intervals - did not differ from Model 2.

Additional detail regarding Models 1-4 is offered by Table 4 where the chance of s-WPS in four categories is compared with actual WPS outcomes. Model 1 did not identify anybody with $<30 \%$ or $\geq 70 \%$ of s-WPS, whereas Model 2 performed better than Model 1, discriminating among those whose chance of s-WPS was very low or very high. The discriminating properties of the models were similar for Models 2, 3 and 4 (assessed by the distribution among categories of chance).

\section{Discussion}

To our knowledge, this is the first study exploring the contribution of demographics, patient-reported, clinical and MRI information to the prediction of work participation in sickness absentees with neck or shoulder pain. The results suggest that demographics and patientreported measures include important prognostic information (sex, duration of sick leave prior to enrollment and ÖMPSQ score) and that neither clinical nor MRI information provide substantial additional information to the prediction of work participation within 2 years. That is, Model 2 performed similarly to Models 3 and 4 regarding sensitivity, specificity, NPV, PPV and AUC.

Table 2 Odds ratios for s-WPS. Results from univariable analyses

\begin{tabular}{|c|c|c|c|}
\hline Demographic information & $\mathrm{N}$ & Odds ratio $(95 \% \mathrm{Cl})$ & $p$-value \\
\hline Male sex & 168 & $1.69(0.85 ; 3.34)^{a}$ & 0.13 \\
\hline Age (years) & 168 & $0.99(0.97 ; 1.03)$ & 0.85 \\
\hline \multicolumn{4}{|l|}{ Patient-reported information } \\
\hline Pain intensity (numeric rating scale) & 161 & $0.98(0.95,1.01)$ & 0.21 \\
\hline Whiplash trauma (yes vs. no) & 168 & $0.77(0.32 ; 1.85)$ & 0.56 \\
\hline Sick leave duration (months) & 168 & $0.68(0.54 ; 0.87)^{a}$ & 0.002 \\
\hline ÖMPSQ score (numerical variable) & 161 & $0.97(0.95 ; 0.98)^{a}$ & $<0.001$ \\
\hline Education $\geq 3$ years (yes vs. no) & 155 & $0.93(0.41 ; 2.12)$ & 0.87 \\
\hline Ongoing worker's compensation claim (yes vs. no) & 139 & $0.45(0.21 ; 0.97)^{\mathrm{a}}$ & 0.04 \\
\hline \multicolumn{4}{|l|}{ Clinical information } \\
\hline Radiculopathy (yes vs. no) & 168 & $4.29(1.77 ; 10.4)^{a}$ & 0.001 \\
\hline$\geq 11$ tender points (yes vs. no) & 168 & $0.58(0.31 ; 1.12)^{a}$ & 0.10 \\
\hline Multidisciplinary intervention & 168 & $1.04(0.56 ; 1.93)$ & 0.90 \\
\hline \multicolumn{4}{|l|}{ MRI information } \\
\hline Kyphosis (yes vs. no) & 97 & $3.06(1.03 ; 9.11)^{a}$ & 0.05 \\
\hline Disc height reduction (yes vs. no) & 97 & $1.40(0.56 ; 3.46)$ & 0.47 \\
\hline Disc contour change (bulge, protrusion or extrusion) (yes vs. no) & 83 & $1.32(0.41 ; 4.24)$ & 0.64 \\
\hline Spinal canal stenosis (yes vs. no) & 97 & $0.31(0.09 ; 1.02)^{\mathrm{a}}$ & 0.06 \\
\hline Neural foraminal stenosis (yes vs. no) & 84 & $1.13(0.47 ; 2.71)$ & 0.78 \\
\hline Zygapophyseal osteoarthritis (yes vs. no) & 83 & $0.81(0.34 ; 1.96)$ & 0.65 \\
\hline Uncovertebral osteoarthritis (yes vs. no) & 78 & $1.44(0.58 ; 3.60)$ & 0.43 \\
\hline
\end{tabular}


Table 3 Predictive values, sensitivity, specificity and AUC for prediction of work participation in each of the multivariable models

\begin{tabular}{|c|c|c|c|c|c|c|}
\hline Information included & $\mathrm{N}$ & $\begin{array}{l}\text { Classified as } \geq 50 \% \text { chance } \\
\text { and achieved s-WPS (NPV) }\end{array}$ & $\begin{array}{l}\text { Classified as }<50 \% \text { chance } \\
\text { and achieved u-WPS } \\
\text { (PPV) }\end{array}$ & $\begin{array}{l}\text { s-WPS correctly } \\
\text { classified (specificity) }\end{array}$ & $\begin{array}{l}\text { u-WPS correctly } \\
\text { classified (sensitivity) }\end{array}$ & $A \cup C$ \\
\hline $\begin{array}{l}\text { Model 1: } \\
\text { Demographic }^{a}\end{array}$ & 168 & $\begin{array}{c}0.60 \\
(0.52 ; 0.67)\end{array}$ & NA & $\begin{array}{c}1.0 \\
(0.96 ; 1.0)\end{array}$ & $\begin{array}{c}0.0 \\
(0.0 ; 0.05)\end{array}$ & $\begin{array}{l}0.56 \\
(0.48 \\
0.63)\end{array}$ \\
\hline $\begin{array}{l}\text { Model 1: } \\
\text { Demographic }\end{array}$ & 139 & $\begin{array}{c}0.59 \\
(0.50 ; 0.67)\end{array}$ & NA & $\begin{array}{c}1.0 \\
(0.96 ; 1.0)\end{array}$ & $\begin{array}{c}0.0 \\
(0.0 ; 0.06)\end{array}$ & $\begin{array}{l}0.56 \\
(0.47 ; \\
0.64)\end{array}$ \\
\hline $\begin{array}{l}\text { Model 2: } \\
\text { Demographic + patient- } \\
\text { reported }\end{array}$ & $139^{\ddagger}$ & $\begin{array}{c}0.72 \\
(0.62 ; 0.81)\end{array}$ & $\begin{array}{c}0.67 \\
(0.52 ; 0.80)\end{array}$ & $\begin{array}{c}0.82 \\
(0.72 ; 0.89)\end{array}$ & $\begin{array}{c}0.54 \\
(0.41 ; 0.68)\end{array}$ & $\begin{array}{c}0.77 \\
(0.69 \\
0.84)\end{array}$ \\
\hline $\begin{array}{l}\text { Model 3: } \\
\text { Demographic + patient- } \\
\text { reported + } \text { clinical }^{c}\end{array}$ & $139^{\ddagger}$ & $\begin{array}{c}0.74 \\
(0.63 ; 0.82)\end{array}$ & $\begin{array}{c}0.69 \\
(0.54 ; 0.81)\end{array}$ & $\begin{array}{c}0.82 \\
(0.71 ; 0.89)\end{array}$ & $\begin{array}{c}0.58 \\
(0.44 ; 0.71)\end{array}$ & $\begin{array}{l}0.78 \\
(0.70 ; \\
0.89)\end{array}$ \\
\hline $\begin{array}{l}\text { Model 3: } \\
\text { Demographic + patient- } \\
\text { reported + clinical }\end{array}$ & 82 & $\begin{array}{c}0.71 \\
(0.59 ; 0.83)\end{array}$ & $\begin{array}{c}0.72 \\
(0.50 ; 0.89)\end{array}$ & $\begin{array}{c}0.87 \\
(0.75 ; 0.95)\end{array}$ & $\begin{array}{c}0.48 \\
(0.31 ; 0.66)\end{array}$ & $\begin{array}{l}0.72 \\
(0.65 ; \\
0.86)\end{array}$ \\
\hline $\begin{array}{l}\text { Model 4: } \\
\text { Demographic + patient- } \\
\text { reported + clinical + MRI }\end{array}$ & $82^{\ddagger}$ & $\begin{array}{c}0.74 \\
(0.60 ; 0.84)\end{array}$ & $\begin{array}{c}0.72 \\
(0.50 ; 0.88)\end{array}$ & $\begin{array}{c}0.86 \\
(0.73 ; 0.94)\end{array}$ & $\begin{array}{c}0.55 \\
(0.36 ; 0.72)\end{array}$ & $\begin{array}{l}0.80 \\
(0.70 ; \\
0.90)\end{array}$ \\
\hline \multicolumn{7}{|c|}{ 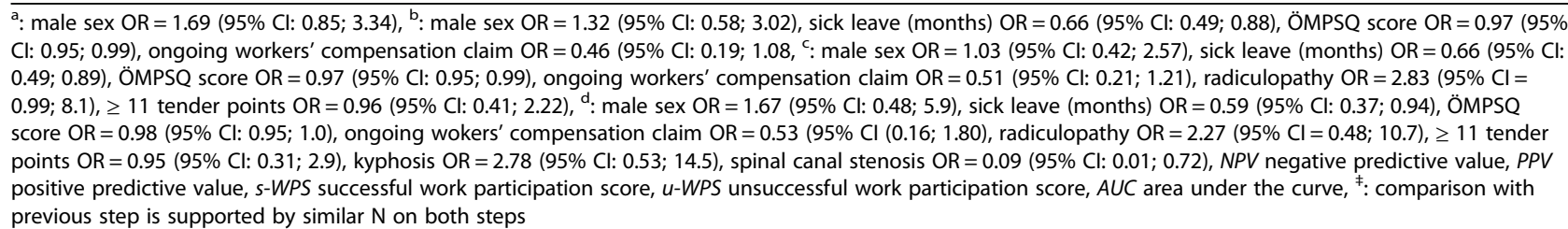 } \\
\hline
\end{tabular}

Model 2 also performed similarly to Models 3 and 4 at discriminating between those having the lowest and highest chance of s-WPS (Table 4).

\section{Comparison with other studies}

$59.5 \%$ of the sickness absentees achieved s-WPS within two-year follow up, which is indicative of a population with a high level of work disability. In a large study of neck and back pain [31], only $8 \%$ reported sick leave the previous year when asked at 3-year follow up. The study [31] was conducted in a workplace setting, hence, study participants were presumably less disabled than those referred to secondary care settings as in the current study. From secondary care settings however, previous studies $[7,32]$ have also found what seemed to be better work outcomes than in the current study. In a study of low back pain, $72 \%$ achieved RTW within 1 year; however RTW was defined as 4 consecutive weeks of work [7]. In another study of primarily musculoskeletal pain, $60 \%$ achieved had a more sustainable RTW outcome at 1 year follow up, namely 3 consecutive months with increased working time compared to baseline [32]. The study population of this study [32] was comprised of sickness absentees referred to a secondary care setting like ours. Hence, we consider the similarity of work outcomes to be indicative of work disability that hampers work participation.
A comprehensive literature search strategy adapted from a 2017 review [2] was performed using Medline and yet, no studies were identified which categorized prognostic variables and used an analytical approach resembling the order of information obtained in a clinical setting. For this reason, direct comparison with previous studies was not possible, but some studies reported measures that can be compared with the current study [33, 34]. In a Norwegian study [33], the sickness absentees' own prediction of sick leave duration $\geq 26$ weeks yielded a slightly better PPV (0.78) than any of the models in the current study. However, the sensitivity based on self-prediction was 0.28 and the sensitivity based on dedicated medical consultants was 0.07 . Both measures are notably lower than the sensitivity estimates of the current study suggesting that 1) perhaps the sickness absentees in Fleten et al.'s study were overoptimistic, leading to a low sensitivity of self-prediction, and 2) the information that was available to the medical consultants [33] was inadequate to result in a sensitivity as high as in the current study.

Rehabilitation professionals in another study [34] predicted the chance of RTW based on sick leave duration, reason for sick leave, unemployment, age $>45$ years, female sex and 'gut feeling'. Their prediction was concordant with actual RTW in $73 \%$ and thus lower than the specificity estimates of all four models in the current study. Of interest is that the rehabilitation professionals 
Table 4 Cross-tabulations showing the classification of chance vs. the achieved work participation score during weeks 1-104 of follow up

\begin{tabular}{|c|c|c|c|c|}
\hline \multirow{2}{*}{$\begin{array}{l}\text { Domains included } \\
\text { Demographics }\end{array}$} & \multicolumn{2}{|l|}{$\mathrm{N}$} & \multicolumn{2}{|l|}{ Outcome } \\
\hline & 168 & Chance of s-WPS & s-WPS & u-WPS \\
\hline & & Chance $<30 \%$ & 0 & 0 \\
\hline & & $30 \% \leq$ chance $<50 \%$ & 0 & 0 \\
\hline & & $50 \% \leq$ chance $<70 \%$ & 100 & 68 \\
\hline & & $\geq 70 \%$ & 0 & 0 \\
\hline \multirow[t]{6}{*}{ Demographic + patient-reported } & 139 & & Outcome & \\
\hline & & Chance of s-WPS & s-WPS & u-WPS \\
\hline & & Chance < $30 \%$ & 7 & 9 \\
\hline & & $30 \% \leq$ chance $<50 \%$ & 8 & 22 \\
\hline & & $50 \% \leq$ chance $<70 \%$ & 25 & 19 \\
\hline & & $\geq 70 \%$ & 42 & 7 \\
\hline \multirow[t]{6}{*}{ Demographic + patient-reported + clinical } & 139 & & Outcome & \\
\hline & & Chance of s-WPS & s-WPS & u-WPS \\
\hline & & Chance $<30 \%$ & 5 & 14 \\
\hline & & $30 \% \leq$ chance $<50 \%$ & 10 & 19 \\
\hline & & $50 \% \leq$ chance $<70 \%$ & 23 & 17 \\
\hline & & $\geq 70 \%$ & 44 & 7 \\
\hline \multirow[t]{6}{*}{ Demographic + patient-reported + clinical + MRI } & 82 & & Outcome & \\
\hline & & Chance of s-WPS & s-WPS & u-WPS \\
\hline & & Chance $<30 \%$ & 3 & 7 \\
\hline & & $30 \% \leq$ chance $<50 \%$ & 4 & 11 \\
\hline & & $50 \% \leq$ chance $<70 \%$ & 15 & 12 \\
\hline & & $\geq 70 \%$ & 27 & 3 \\
\hline
\end{tabular}

WPS work participation score, s-WPS successful work participation score, i.e. WPS $\geq 50 \%$ in weeks $1-104$, u-WPS unsuccessful work participation score, i.e. WPS $<$ $50 \%$ in weeks $1-104$

in that study [34] had access to some similar information as was available in the current study, namely sex and sick leave duration. But in spite of their access to further information about reason for sick leave, unemployment, age $>45$ and "gut feeling", specificity estimates similar to the current study were not achieved.

Regarding the association between sex and work outcomes, results in previous studies have been conflicting. In a population-based study [35] and in studies from secondary care on spinal pain [36] and shoulder pain [37], sex was not associated with work outcomes, while a primary care study [28] did find predictive value of sex. In summary, reviews have found conflicting evidence on the impact of sex on work outcomes [1, 3, 28, 35-37] and with this in mind, the current study's estimates in Model 1 based on sex alone are not surprising.

The impact of sick leave duration corroborates the findings in numerous reviews $[1,3,8,38,39]$ and cohort studies of both shoulder pain, spinal pain and whiplash trauma $[28,40,41]$. Due to the non-modifiable nature of sick leave duration, our findings highlight the need for action that prevents and/or addresses sick leave early enough to minimize the duration.

The ÖMPSQ score covers psychosocial risk factors of work disability (e.g. feelings of anxiety or depression and self-perceived chances of returning to work in 6 months). The negative association between the ÖMPSQ score and s-WPS is in line with previous findings [21, 42]. While studies from primary care settings and workplaces $[43,44]$ have suggested ÖMPSQ cut-off values of 90 and 105, the current study suggests that in a secondary care setting, ÖMPSQ has important properties regarding prognosis of work participation also as a discrete variable.

Interestingly, a study of primarily chronic spinal pain suggested cut-offs of 90 and 105 [44] but did not yield sensitivity and specificity measures that were concurrently as high as any of the models including ÖMPSQ in the current study. In contrast, a primary care study of patients with acute or sub-acute spinal pain [43], a cut- 
off of 90 yielded better sensitivity and slightly lower specificity [43], thereby demonstrating the properties of ÖMPSQ in early detection of poor work prognosis.

The negative association between ongoing workers' compensation claim and s-WPS is in line with the findings of a previous Danish study of patients with neck/ arm pain or back/leg pain [4].

In the context of clinical variables, a cohort study on low back pain [45] found a crude association between tender points count (discrete variable) and unsuccessful RTW. However, this was not maintained in the multivariable model. Moreover, no association was found between radiculopathy and work outcomes [45], which was supported by a review presenting moderate evidence for no association between radiating pain and RTW [2]. Therefore, our finding of the limited improvement of predictive values in Model 3 is in line with these previous findings $[2,45]$.

Finally, regarding MRI, only one study was identified which explored the association between MRI findings and work outcomes [7]. In this study of sickness absentees with low back pain, the presence of Modic type 1 changes was associated with unsuccessful RTW. Unfortunately, we were unable to assess the impact of Modic changes in the current study since the inter- and intrarater reliability for this pathology was not established owing to too low prevalences [27].

\section{Methodological considerations}

WPS was chosen as the outcome measure in an attempt to capture both work reintegration and work maintenance although we are aware that other RTW outcomes reflect other aspects regarding the process and context of RTW [46]. The chosen cut-off value (s-WPS $\geq 50 \%$ or not) showed substantial to almost perfect agreement with other RTW measures (RTW yes/no at a given time point and time to 4 weeks of self-support without relapses, respectively) in a previous study [17]. The same study [17] found WPS suitable for prognostic purposes. When classifying the chance of s-WPS, a $50 \%$ threshold was chosen for two reasons: 1) A reasonable balance between sensitivity and specificity measures was desired and 2) Our clinical experience suggests that sickness absentees with neck or shoulder pain who are seen in secondary care are troubled with many biopsychosocial issues. Hence, choosing higher cut-offs for the chance of s-WPS might be too optimistic. A different cut-off would probably be relevant if the study population had comprised patients from primary care on short-term sick leave.

Inclusion of more variables (e.g. more patient-reported, clinical or occupational information) was not possible owing to power considerations.

\section{Strengths}

First, the use of registry data for the outcome assessment ensured $100 \%$ follow up thereby reducing the risk of attrition bias. Second, the use of registry data reduced the risk of measurement bias since the outcome assessment was unaffected by knowledge of the prognostic variables. Likewise, the assessment of prognostic factors was unaffected by knowledge of the outcome. Third, the risk of attrition bias was minimized by the low number of missing values for the majority of variables (demographic, patient-reported and clinical variables). Only for MRI was the number of missing values substantial. However, the distribution between exposure and outcome was assessed for all the variables in Table 1, which revealed that attrition was not skewed for any of the variables, hence attrition bias was not suspected (data not shown). Fourth, the duration of follow up reaching 2 years constitutes a realistic long-term outcome. A fifth strength is the a priori decision to take an analytical approach resembling the working conditions of the clinicians who are responsible for appraisal of work prognosis. This reduced the risk of purely data-driven results. Sixth, the risk of bias owing to potential misclassification of MRI findings was minimal owing to high levels of observed agreement for kyphosis and spinal canal stenosis [27]. Finally, when bearing in mind the well-established impact of external societal factors on the process of sick leave $[47,48]$, it is a further strength of the current study that the Danish legislation on sickness benefits did not undergo major changes from 2009 to 2014. A change in legislation in 2014 reduced the right for sickness benefits from 52 to 22 weeks. It affected only six sickness absentees (four achieved s-WPS and two did not) and is thus not suspected to bias the estimates.

\section{Limitations}

First, since the study population was originally included in an RCT, the results may not be generalizable to all sickness absentees with neck or shoulder pain. The possibility of sampling bias due to referral patterns of the general practitioners cannot be refuted nor elucidated. Hence, the results are expected to be representative of sickness absentees with neck or shoulder pain who are seen in a secondary care setting. Generalizability to primary care settings should be made with caution and confirmatory studies including all sickness absentees with neck or shoulder pain would be needed to improve generalizability.

Second, the representativeness of the results should be considered in the light of the above-mentioned change in legislation, implying that the right to sickness benefits is now limited to 22 weeks compared with 52 weeks during most of the study. Confirmatory studies would be desirable to assess the impact of this change in legislation. But 
given that the literature over the past decades is corroborated (i.e. major impact of sick leave duration and psychosocial factors [49]), we expect that similar results would be found.

Third, the limited MRI sample affects precision of the estimates; an issue that was further attenuated for certain MRI variables (disc bulge/protrusion/extrusion, neural foraminal stenosis, zygapophyseal osteoarthritis and uncovertebral osteoarthritis). For these variables, the available sequences did not allow for evaluation on all 97 MRIs (Table 1 and [27]). Had MRI been available for the entire cohort, confidence intervals for MRI variables would have been narrowed down.

Fourth, the use of registry data is usually an advantage, but the data source also warrants consideration since registration procedures imply a risk of unequal registration of short-term sick leave. Sick leave registration in DREAM begins at the end of the employer paid period and backward adjustments are made, so that the number of sickness benefit weeks in DREAM equal the total number of sick leave weeks. Since registration is initiated at the end of the employer paid period, multiple absences due to sick leave lasting only days or a few weeks are usually not registered (because they are within the employer-paid period). In the current study, some participants may have been misclassified as having achieved $\mathrm{s}$-WPS although they had multiple short-term absences due to sick leave. A related problem applies to employees with a \$56-agreement, i.e. their employers are entitled to reimbursement of sickness benefits from day one; such employees may be misclassified as u-WPS in the current study due to sick leave registrations exceeding actual duration. These possible misclassifications are considered non-differentiated since they are not suspected to be associated with the exposure (i.e. the prognostic variables). Unfortunately, the data do not offer any insight as to the possible distribution of $\$ 56$-agreements in the current study. However, explorative posthoc analyses were performed in which single weeks of sickness benefit reimbursement were considered as $\$ 56$ agreements, i.e. regarded as working weeks. This resulted in the distribution of s-WPS/u-WPS changing from $100 / 68$ to $102 / 66$ (data not shown). It did not change the results of the study.

Sixth, the limited sample size implies a risk of type II errors. That is, important prognostic factors may not be discovered as statistically significant owing to the limited sample size. Other factors that could affect the prognosis for work outcomes include fear avoidance beliefs [2, 3, $49]$ and physical workload [1, 2, 39]. These factors were not isolated for analysis in the current study since they were covered by the ÖMPSQ score and we wished for all variables to be as mutually exclusive as possible. Furthermore, the aim was not to investigate a complete list of all possible factors affecting WPS prognosis but rather to explore the contributions of demographic, patientreported, clinical and MRI variables for which purpose we believe the current sample size was adequate.

\section{Conclusions}

In this study of sickness absentees with neck or shoulder pain, clinical and MRI information provided no additional information for the prediction of work participation compared with only demographic and patientreported information.

Though Model 2 performs similarly to Models 3 and 4 , there are limitations with respect to discriminating between those with the lowest and highest chance of sWPS. This means that clinical applicability requires caution if the aim is identification of those who have the lowest/highest chances of s-WPS. The results do, however, provide valuable knowledge to clinicians both in the assessment of work prognosis and in dialogue with patients and other stakeholders: prediction should primarily be based on demographic and patient-reported information, not on clinical and MRI findings.

Due to the exploratory nature of the current study, the generalizability of findings needs to be assessed in independent studies, preferably in both primary and secondary care settings.

\section{Abbreviations \\ AUC: Area Under the Curve; DREAM: Danish Register for Evaluation of Marginalization; MRI: Magnetic Resonance Imaging; NPV: Negative Predictive Value; ÖMPSQ: Örebro Musculoskeletal Pain Screening Questionnaire; PPV: Positive Predictive Value; RCT: Randomized Controlled Trial; RTW: Return To Work; s-WPS: Successful Work Participation Score; u-WPS: Unsuccessful Work Participation Score; WPS: Work Participation Score}

\section{Acknowledgements}

Not applicable.

\section{Authors' contributions}

LTM contributed to the design of the study, performed the MRI assessments, analysed and interpreted the data, and wrote the manuscript. CMS, ML, OK, TSJ and BSC contributed to the design of the study and contributed to the interpretation of data and revision of the manuscript. OKJ collected the clinical data. AMS and MWK contributed to the interpretation of data and revision of the manuscript. All the authors critically revised and approved the final manuscript.

\section{Funding}

The current study was funded by Aarhus University Denmark, The Tryg Foundation, Aase and Ejnar Danielsen Foundation, and The Danish Rheumatism Association. None of these were involved in the design, data collection, data analyses, data interpretation or conclusions.

\section{Availability of data and materials}

The datasets used and/or analysed during the current study are available from the corresponding author on reasonable request.

Ethics approval and consent to participate

All participants provided written informed consent. The study was approved by The Danish Data Protection Agency (J. no. 2012-58-006) and by The Central Denmark Region Committees onHealth Research Ethics (M-20090027). 


\section{Consent for publication}

Not applicable.

\section{Competing interests}

The authors declare that they have no competing interests.

\section{Author details}

'DEFACTUM, P.P. Oerums Gade 11, bygn. 1B, Aarhus C, DK-8000 Aarhus, Central Denmark Region, Denmark. ${ }^{2}$ Section of Clinical Social Medicine and Rehabilitation, Department of Public Health, Aarhus University, P.P. Oerums Gade 9-11, bygn. 1B, Aarhus C, DK-8000 Aarhus, Denmark. ${ }^{3}$ Spine Centre, Diagnostic Centre, Silkeborg Regional Hospital, Falkevej 1-3, DK-8600 Silkeborg, Denmark. ${ }^{4}$ Sano Aarhus, Egernvej 5, DK-8270 Højbjerg, Aarhus, Denmark. ${ }^{5}$ Department for Diagnostic Imaging, Diagnostic Centre, Silkeborg Regional Hospital, University Research Clinic for Innovative Patient Pathways, Falkevej 1-3, DK-8600 Silkeborg, Denmark. ${ }^{6}$ Nordic Institute of Chiropractic and Clinical Biomechanics, University of Southern Denmark, Campusvej 55 Odense M, DK-5230 Odense, Denmark. ${ }^{7}$ Spine Centre of Southern Denmark, Hospital Lillebaelt Middelfart and Institute of Regional Health Research, University of Southern Denmark, Oestre Hougvej 55 Middelfart, DK-5500 Odense, Denmark

Received: 4 March 2019 Accepted: 22 October 2019 Published online: 09 November 2019

\section{References}

1. Cancelliere C, Donovan J, Stochkendahl MJ, Biscardi M, Ammendolia C,

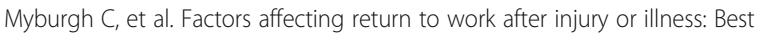
evidence synthesis of systematic reviews. Chiropr Man Therap. 2016;24(1): 32,016-0113-z eCollection 2016.

2. Steenstra IA, Munhall C, Irvin E, Oranye N, Passmore S, Van Eerd D, et al. Systematic review of prognostic factors for return to work in workers with sub acute and chronic low back pain. J Occup Rehabil. 2017 Sep;27(3):369-81.

3. Rinaldo U, Selander J. Return to work after vocational rehabilitation for sicklisted workers with long-term back, neck and shoulder problems: a followup study of factors involved. Work. 2016 Sep 27;55(1):115-31.

4. Hestbaek L, Rasmussen C, Leboeuf-Yde C. Financial compensation and vocational recovery: a prospective study of secondary care neck and back patients. Scand J Rheumatol. 2009 Nov-Dec;38(6):481-7.

5. Hulshof C, Pransky G. Handbook of work disability. In: Loisel P, Anema JR, editors. Handbook of Work Disability. 1st ed. New York: Springer Science+ Business Media; 2013. p. 203.

6. Palstam A, Mannerkorpi K. Work ability in fibromyalgia: an update in the 21st century. Curr Rheumatol Rev. 2017;13(3):180-7.

7. Jensen OK, Nielsen CV, Sorensen JS, Stengaard-Pedersen K. Type 1 modic changes was a significant risk factor for 1-year outcome in sick-listed low back pain patients: a nested cohort study using magnetic resonance imaging of the lumbar spine. Spine J. 2014 Nov 1:14(11):2568-81.

8. Carroll LJ, Hogg-Johnson S, Cote P, van der Velde G, Holm LW, Carragee EJ, et al. Course and prognostic factors for neck pain in workers: results of the bone and joint decade 2000-2010 task force on neck pain and its associated disorders. Spine (Phila Pa 1976). 2008 Feb 15;33(4 Suppl):S93-100.

9. Christensen Al, Davidsen M, Juel K. The national health profile 2013; 2014.

10. Jensen HAR, Davidsen M, Christensen Al. The national health profile 2017; 2018.

11. National danish patient registry . Available from: http://www.esundhed.dk/ sundhedsregistre/LPR/Sider/LPR04_Tabel.aspx.

12. Misailidou V, Malliou P, Beneka A, Karagiannidis A, Godolias G. Assessment of patients with neck pain: a review of definitions, selection criteria, and measurement tools. J Chiropr Med. 2010 Jun:9(2):49-59.

13. Murphy RJ, Carr AJ. Shoulder pain. BMJ Clin Evid. 2010 Jul 22;2010:1107.

14. Moll LT, Jensen OK, Schiottz-Christensen B, Stapelfeldt CM, Christiansen DH, Nielsen CV, et al. Return to work in employees on sick leave due to neck or shoulder pain: a randomized clinical trial comparing multidisciplinary and brief intervention with one-year register-based follow-up. J Occup Rehabil. 2018; 28(2):346-56. https://doi.org/10.1007/s10926-017-9727-9.

15. Danish sickness benefit act 2014. Available from: https://www retsinformation.dk/Forms/R0710.aspx?id=161736\#Kap8.

16. Stapelfeldt CM, Jensen C, Andersen NT, Fleten N, Nielsen CV. Validation of sick leave measures: Self-reported sick leave and sickness benefit data from a danish national register compared to multiple workplace-registered sick leave spells in a danish municipality. BMC Public Health. 2012;12:661 2458-12-661.
17. Biering $\mathrm{K}, \mathrm{Hjollund} \mathrm{NH}$, Lund $\mathrm{T}$. Methods in measuring return to work: a comparison of measures of return to work following treatment of coronary heart disease. J Occup Rehabil. 2013 Sep;23(3):400-5.

18. Bolton JE, Humphreys BK, van Hedel HJ. Validity of weekly recall ratings of average pain intensity in neck pain patients. J Manip Physiol Ther. 2010 Oct; 33(8):612-7.

19. Biering-Sorensen S, Moller A, Stoltenberg CD, Holm JW, Skov PG. The return-to-work process of individuals sick-listed because of whiplashassociated disorder: A three-year follow-up study in a danish cohort of long-term sickness absentees. BMC Public Health. 2014;14: 113,2458-14-113.

20. Loisel P, Cote P. Handbook of work disability. In: Loisel P, Anema JR, editors. 1st ed. New York: Springer Science+Business Media; 2013. p. 59.

21. Karran EL, McAuley JH, Traeger AC, Hillier SL, Grabherr L, Russek LN, et al. Can screening instruments accurately determine poor outcome risk in adults with recent onset low back pain? A systematic review and metaanalysis. BMC Med. 2017;15(1):13,016 -0774-4.

22. Kasch H, Qerama E, Kongsted A, Bach FW, Bendix T, Jensen TS. Deep muscle pain, tender points and recovery in acute whiplash patients: a 1-year followup study. Pain. 2008;140(1):65-73.

23. Jensen OK, Nielsen CV, Stengaard-Pedersen K. One-year prognosis in sicklisted low back pain patients with and without radiculopathy. Prognostic factors influencing pain and disability. Spine J. 2010 Aug;10(8):659-75.

24. Jensen OK, Callesen J, Nielsen MG, Ellingsen T. Reproducibility of tender point examination in chronic low back pain patients as measured by intrarater and inter-rater reliability and agreement: A validation study. BMJ Open. 2013;3(2). https://doi.org/10.1136/bmjopen,2012-002532 Print 2013.

25. Wolfe F, Smythe HA, Yunus MB, Bennett RM, Bombardier C, Goldenberg DL, et al. The american college of rheumatology 1990 criteria for the classification of fibromyalgia. Report of the multicenter criteria committee. Arthritis Rheum. 1990 Feb;33(2):160-72.

26. Clauw DJ. Chapter 77. fibromyalgia and related syndromes. In: Hochberg MC, Silman AJ, Smolen JS, Weinblatt ME, Weisman MH, editors. Rheumatology. 5th ed. Philadelphia: Elsevier Ltd; 2011. p. 769.

27. Moll LT, Kindt MW, Stapelfeldt CM, Jensen TS. Degenerative findings on MRI of the cervical spine: An inter- and intra-rater reliability study. Chiropr Man Therap. 2018;26:43,018-0210-2 eCollection 2018.

28. Kuijpers $T$, van der Windt DA, van der Heijden GJ, Twisk JW, Vergouwe $Y$, Bouter LM. A prediction rule for shoulder pain related sick leave: A prospective cohort study. BMC Musculoskelet Disord. 2006;7:97 2474-7-97.

29. Rudbeck M, Jensen SL, Fonager K. Arthroscopic subacromial decompression and predictors of long-term sick leave benefit and permanent benefits. J Shoulder Elb Surg. 2013 Sep;22(9):1167-72.

30. Herbert RD. Cohort studies of aetiology and prognosis: They're different. J Physiother. 2014;60(4):241-4

31. Bergstrom $G$, Bodin L, Bertilsson $H$, Jensen IB. Risk factors for new episodes of sick leave due to neck or back pain in a working population. A prospective study with an 18-month and a three-year follow-up. Occup Environ Med. 2007:64(4):279-87.

32. Brendbekken R, Vaktskjold A, Harris A, Tangen T. Predictors of return-to-work in patients with chronic musculoskeletal pain: a randomized clinical trial. J Rehabil Med. 2018;50(2):193-9.

33. Fleten $\mathrm{N}$, Johnsen $\mathrm{R}$, Forde $\mathrm{OH}$. Length of sick leave - why not ask the sicklisted? sick-listed individuals predict their length of sick leave more accurately than professionals. BMC Public Health. 2004;4:46 2458-4-46.

34. von Celsing AS, Svardsudd K, Wallman T. Predicting return to work among sickness-certified patients in general practice: properties of two assessment tools. Ups J Med Sci. 2014;119(3):268-77.

35. Haukka E, Ojajarvi A, Kaila-Kangas L, Leino-Arjas P. Protective determinants of sickness absence among employees with multisite pain-a 7-year followup. Pain. 2017;158(2):220-9.

36. Elfving $\mathrm{B}$, Asell $\mathrm{M}$, Ropponen A, Alexanderson $\mathrm{K}$. What factors predict full or partial return to work among sickness absentees with spinal pain participating in rehabilitation? Disabil Rehabil. 2009;31(16):1318-27.

37. Engebretsen K, Grotle M, Bautz-Holter E, Ekeberg OM, Brox Jl. Predictors of shoulder pain and disability index (SPADI) and work status after 1 year in patients with subacromial shoulder pain. BMC Musculoskelet Disord. 2010; $11 \cdot 218$ 2474-11-218

38. Carroll LJ, Hogg-Johnson S, van der Velde G, Haldeman S, Holm LW, Carragee EJ, et al. Course and prognostic factors for neck pain in the general population: results of the bone and joint decade 2000-2010 task 
force on neck pain and its associated disorders. Spine (Phila Pa 1976). 2008; 33(4 Suppl):S75-82.

39. Desmeules F, Braen C, Lamontagne M, Dionne CE, Roy JS. Determinants and predictors of absenteeism and return-to-work in workers with shoulder disorders. Work. 2016;55(1):101-13.

40. Carstensen TB, Fink P, Oernboel E, Kasch H, Jensen TS, Frostholm L. Sick leave within 5 years of whiplash trauma predicts recovery: a prospective cohort and register-based study. PLoS One. 2015;10(6):e0130298.

41. Lindell O, Johansson SE, Strender LE. Predictors of stable return-to-work in non-acute, non-specific spinal pain: Low total prior sick-listing, high self prediction and young age. A two-year prospective cohort study. BMC Fam Pract. 2010;11:53 2296-11-53.

42. Hockings RL, McAuley JH, Maher CG. A systematic review of the predictive ability of the Orebro musculoskeletal pain questionnaire. Spine (Phila Pa 1976). 2008:33(15):E494-500.

43. Linton SJ, Boersma K. Early identification of patients at risk of developing a persistent back problem: the predictive validity of the Orebro musculoskeletal pain questionnaire. Clin J Pain. 2003;19(2):80-6.

44. Bergstrom G, Hagberg J, Busch H, Jensen I, Bjorklund C. Prediction of sickness absenteeism, disability pension and sickness presenteeism among employees with back pain. J Occup Rehabil. 2014;24(2):278-86.

45. Jensen OK, Stengaard-Pedersen K, Jensen C, Nielsen CV. Prediction model for unsuccessful return to work after hospital-based intervention in low back pain patients. BMC Musculoskelet Disord. 2013:14:140 2474-14-140.

46. Wasiak R, Young AE, Roessler RT, McPherson KM, van Poppel MN, Anema JR. Measuring return to work. J Occup Rehabil. 2007;17(4):766-81.

47. Loisel P. Durand M-, Berthelette D, Vézina N, Baril R, Gagnon D, et al. disability prevention. New paradigm for the management of occupational back pain. Dis Manage Health Outcomes. 2001;9(7):351-60.

48. Werner EL, Cote P. Low back pain and determinants of sickness absence. Eur J Gen Pract. 2009;15(2):74-9.

49. Bültmann U, Brouwer S. Handbook of work disability. In: Loisel P, Anema J, editors. . 1st ed. New York: Springer Science+Business Media; 2013. p. 149

\section{Publisher's Note}

Springer Nature remains neutral with regard to jurisdictional claims in published maps and institutional affiliations.

Ready to submit your research? Choose BMC and benefit from:

- fast, convenient online submission

- thorough peer review by experienced researchers in your field

- rapid publication on acceptance

- support for research data, including large and complex data types

- gold Open Access which fosters wider collaboration and increased citations

- maximum visibility for your research: over $100 \mathrm{M}$ website views per year

At $\mathrm{BMC}$, research is always in progress.

Learn more biomedcentral.com/submissions 